\title{
Sophorolipids Production from Oil Cake by Solid-State Fermentation. Inventory for Economic and Environmental Assessment
}

\author{
Alejandra Rodriguez, Teresa Gea* and Xavier Font \\ Composting Research Group, Department of Chemical, Biological and Environmental Engineering, Escola d'Enginyeria, \\ Universitat Autònoma de Barcelona, Barcelona, Spain
}

\section{OPEN ACCESS}

Edited by:

Chang Geun Yoo,

SUNY College of Environmental Science and Forestry, United States

Reviewed by:

Zhi-Hua Liu,

Texas A\&M University,

United States

Deepak Kumar,

SUNY College of Environmental Science and Forestry, United States

*Correspondence:

Teresa Gea

teresa.gea@uab.cat

Specialty section:

This article was submitted to Environmental Chemical Engineering,

a section of the journal

Frontiers in Chemical Engineering

Received: 23 November 2020

Accepted: 08 February 2021

Published: 26 March 2021

Citation:

Rodríguez A, Gea T and Font X (2021) Sophorolipids Production from Oil Cake by Solid-State Fermentation.

Inventory for Economic and

Environmental Assessment.

Front. Chem. Eng. 3:632752.

doi: $10.3389 /$ fceng.2021.632752
Biosurfactants are being proposed as a substitute for surfactants in the framework of a circular economy strategy. Sophorolipids (SL) are a type of biosurfactant produced by yeast that can be produced through submerged or solid-state fermentation (SSF) processes. Even though sophorolipids are being produced at full scale, through submerged fermentations, environmental and technoeconomic information regarding its production through SSF is unavailable. An inventory of data necessary to perform preliminary economic and environmental assessments is presented in this study. Data was obtained from three SSF processes at 22- $L$ reactor volume and from two SSF processes at $100-L$ reactor volume, using winterization oil cake and molasses as substrates, wheat straw as support material, and Starmerella bombicola as SL producing yeast. The effect of increasing the operation scale was assessed. Besides presenting parameters such as inoculum production, initial mass of substrates, and airflow requirements; process emissions $\left(\mathrm{NH}_{3}\right.$, Volatile Organic Compounds, $\mathrm{N}_{2} \mathrm{O}, \mathrm{SH}_{2}$ and $\left.\mathrm{CH}_{4}\right)$ and the biogas potential of the spent fermentation solids were also presented.

Keywords: biosurfactant, sophorolipid, solid-state fermentation, oil-cake, wheat straw, economic, LCA, inventory

\section{INTRODUCTION}

Biosurfactants (BS) are becoming increasingly attractive in the market, industry, and scientific community. Substituting classical chemical surfactants with bio-based surfactants presents several environmental benefits. Not only does it avoid the spread of toxic compounds to humans and animals in the environment but it also boosts the circular economy. In this circular economy framework, the use of wastewaters, solid waste, and byproducts as substrates for fermentation processes is a key point to close material cycles. Efforts are therefore devoted to demonstrating the potential of wastes and side-streams as substrates for BS production. The use of wastewaters to produce BS can be found in the literature (Daverey et al., 2011), however, in solid wastes this is very rare (Banat et al., 2014; Jiménez-Peñalver et al., 2019). Material valorization of solid wastes to produce bioproducts can be achieved through solid-state fermentation processes. Solid-state fermentation (SSF) is an emerging technology that allows using non-soluble solid substrates as growing media to produce many diverse compounds, from enzymes to aroma, including biosurfactants (Banat et al., 2021). In some cases, e.g., production of biosurfactants such as sophorolipids, the fermentation media should include hydrophilic and hydrophobic substrates, the latter having low water solubility. In these cases, SSF can take advantage of submerged fermentation processes, paving the way for the valorization of a broad type of solid substrates. 
In this framework, and as demonstrated in our previous studies, we have shown the potential of winterization oil cake as a hydrophobic substrate for sophorolipid production with $S$. bombicola through SSF (Jiménez-Peñalver et al., 2016) at lab scale, and the suitability of lignocellulosic, agricultural byproducts as support materials (Rodríguez et al., 2020). Our results are promising, with yields close to $0.2 \mathrm{~g} \mathrm{SL} \mathrm{g}^{-1}$ substrate and productivities around $2.7 \mathrm{~g} \mathrm{SL} \mathrm{L}^{-1} \mathrm{~d}^{-1}$.

Literature highlights several advantages of SSF over traditional submerged fermentation, including lower water requirements, the obvious potential to accept solid wastes as substrates in the circular economy framework and, specifically for the case of BS, the absence of foaming during fermentation. However, solid-state fermentation systems present some drawbacks and challenges in their commercialization. Organic solids are poor heat conductors, so the metabolic heat released in the fermentation accumulates in the solid matrix, inducing a temperature increase. Tray reactors, traditionally used, limit bed height but require a greater surface as well as human resources (Mitchell et al., 2006). Packed-bed bioreactors have been proposed for scaling-up SSF (da Cunha et al., 2020). When using this type of bioreactor, severe temperature gradients are frequently observed when scaling up and temperature values can easily go over the desired process conditions for optimal production (Pitol et al., 2016; Perez et al., 2019). This issue can be especially relevant when using fatenriched substrates (Gea et al., 2007), as is the case of residual oil cakes for BS production. It is necessary to analyze temperature dynamics when increasing the scale in SSF systems to establish their technical viability.

It is also necessary to gather quality data to perform preliminary economic and environmental assessment of the proposed production system. Again, some literature can be found regarding SL production through submerged fermentation, including Life Cycle Assessment (Baccile et al., 2016; Hu et al., 2021) and economic assessment (Wang et al., 2020). However, no literature can be found regarding SL production through SSF. The early assessment of technical, economic, and environmental viability is essential prior to investing more efforts in developing the process at a commercial scale and will help in identifying improvement opportunities.

The goal of this work was to analyze the performance of SL production by SSF with Starmerella bombicola, using winterization oil cake and molasses as substrates and wheat straw as support material, at a representative bench-scale; to measure direct process emissions; and to analyze biodegradability of fermented solids after SLs extraction; to build a complete inventory dataset and to establish the basis for further economic and environmental assessments of the process.

\section{MATERIALS AND METHODS}

\section{Materials and Mixtures}

Winterization Oil Cake (WOC) is the cake obtained after submitting sunflower oil to low temperatures below $5^{\circ} \mathrm{C}$ to crystalize waxes and to filter with perlite. WOC (95.6\% dry mass and $44-70 \%$ organic matter equivalent to hexane extractable material) was provided by Lípidos Santiga, S.A. (Barcelona, Spain). Sugar beet molasses (MOL, 82.9\% dry mass, $87.1 \%$ organic matter) were provided by $A B$ Azucarera Iberia S.L.U. (Madrid, Spain). Wheat straw (WS, 94.4\% dry mass, 95.5\% organic matter) was obtained from the farms at the Veterinary School (Universitat Autònoma de Barcelona, Barcelona, Spain).

The specific conditions for the solid mixture composition (substrate ratios, support, moisture, etc.) were selected in previous work (Jiménez-Peñalver, 2017; Rodríguez et al., 2020). The fermentation mixture was prepared by mixing WS and WOC and by adding MOL diluted in the amount of water necessary to reach $75 \%$ of WS water holding capacity. WOC: MOL mass ratio was 4:1. WS was sterilized twice prior to mixing $\left(121^{\circ} \mathrm{C}, 30 \mathrm{~min}\right)$. The mixture was sterilized $\left(121^{\circ} \mathrm{C}, 30 \mathrm{~min}\right)$ once prior to inoculation. The final moisture content of the initial mixture after sterilization was $46 \%$.

Spent fermented solids (solids at the end of fermentation after SLs extraction and evaporation of solvent) were $93.4 \%$ dry mass and $83.2 \%$ organic matter.

\section{Inoculum Preparation}

Starmerella bombicola ATCC 22214 was purchased from the American Type Culture Collection (Manassas, United States). Cryopearls were reactivated on agar plates containing: $10 \mathrm{~g} / \mathrm{L}$ of dextrose; $5 \mathrm{~g} / \mathrm{L}$ of peptone; $3 \mathrm{~g} / \mathrm{L}$ of malt extract; $3 \mathrm{~g} / \mathrm{L}$ of yeast extract, and $20 \mathrm{~g} / \mathrm{L}$ of bacteriological agar for $48 \mathrm{~h}$ at $30^{\circ} \mathrm{C}$. Four bacteriological loops were added to $1 \mathrm{~L}$ Erlenmeyer flasks with $200 \mathrm{ml}$ of culture medium: $10 \mathrm{~g} / \mathrm{L}$ of dextrose; $5 \mathrm{~g} / \mathrm{L}$ of peptone; $3 \mathrm{~g} / \mathrm{L}$ of malt extract and $3 \mathrm{~g} / \mathrm{L}$ of yeast extract. The flasks were incubated in a shaker for $48 \mathrm{~h}$ at $30^{\circ} \mathrm{C}$ and $180 \mathrm{rpm}$.

\section{Fermentation Systems}

Two bioreactors were used in this work. They consisted of cylindrical stainless-steel fermenters with an helicoidal mixer. A perforated dish separates the solids chamber from the air distribution chamber. Air from an airflow meter is fed into the bottom and flows to the exit at the top of the bioreactor, where it is sent to an oxygen sensor. Supplementary Figures S11, S12 present a complete scheme of both fermentation systems. The characteristics of the solids chamber for each system were:

i. System R22: volume $22 \mathrm{~L}$, diameter/height ratio 0.5 and wall surface/volume $16.5 \mathrm{~m}^{2} / \mathrm{m}^{3}$;

ii. System R100: volume $100 \mathrm{~L}$, diameter/height ratio 0.575 and wall surface/volume $8.7 \mathrm{~m}^{2} / \mathrm{m}^{3}$.

The specific conditions for fermentation, such as aeration rates and fermentation time, were selected in previous work (JiménezPeñalver, 2017; Rodríguez et al., 2020). Bioreactors were filled up to $75 \%$ and $60 \%$ of their working capacity for R22 and R100, respectively. R22 worked with $3.000 \mathrm{~kg}$ of wet mass, including $1.012 \mathrm{~kg}$ of WOC, $0.253 \mathrm{~kg}$ of MOL, and $0.610 \mathrm{~kg}$ of WS. R100 worked with $10.5 \mathrm{~kg}$ of total mass (including 3.541, 0.885 and $2.137 \mathrm{~kg}$ of WOC, MOL and WS respectively). 
The system was aerated to ensure a sufficient oxygen content over $15 \%$ at any moment. A specific aeration rate of $0.33 \mathrm{~L}$ of air per $\mathrm{kg}$ of total mass and per hour was used to start the fermentation in both $\mathrm{R} 22$ and $\mathrm{R} 100$ replicates. When temperature increased over $35^{\circ} \mathrm{C}$ (after $48-72 \mathrm{~h}$ ), airflow was increased to assist heat removal to 31.7 (first replicate) and 26.2 (second and third replicates) in R22 and up to $34.4 \mathrm{~L}$ $\mathrm{kg}^{-1} \mathrm{~h}^{-1}$ in R100. Aeration was sufficient, since the oxygen concentration in the exhaust gas was always over $14.8 \%$.

The total fermentation time was 7 days. R22 replicates 1 and 2 were sampled at day 3,5, and 7 . The third R22 replicate was not sampled to avoid contamination. R100 replicates were sampled at day 4,6 , and 7 .

The temperature was monitored with $12 \mathrm{~T}$ button sensors (iButton, Thermochron, United Kingdom) that were distributed in the solid matrix at different radial and axial positions. Specifically, four sensors were placed at 25, 50, and $75 \%$ bed height, in positions at the center, half the radius (x2), and the wall. Room temperature was kept between 19 and $23^{\circ} \mathrm{C}$ for R22L. R100 was located in a different building and room temperature oscillated between 20 and $25^{\circ} \mathrm{C}$.

The mixer was activated for $2 \mathrm{~min}$ at $5 \mathrm{~Hz}$ before sampling in R22 replicates 1 and 2. Mixing was not planned in the R100 experiments because in previous experiments we detected the compaction of material against the bioreactor baffles that would hinder the fermentation.

\section{Analytical Methods}

SLs were extracted from the solid samples with ethyl acetate as described previously by Rodríguez et al. (2020). Briefly, two consecutive extractions ( $1 \mathrm{~h}, 200 \mathrm{rpm}$, room temperature) were done using a ratio of solids:solvent 1:10 (w/v). The two extracts were mixed and filtered with Whatman paper, and vacuum dried with a rotary evaporator at $40^{\circ} \mathrm{C}$. The resulting SLs were washed with n-hexane twice to remove impurities. SLs yield is reported herein as $g$ SLs per $g$ of initial dry mass in the fermenter. We also provide volumetric yield and productivity (considering the volume of bed in the reactor) and product/substrate yield ( $\mathrm{g}$ SLs $\mathrm{g}^{-1}$ substrates), considering the amount of WOC and MOL.

Gaseous emissions produced in the fermentation were quantified as described by Maulini-Duran et al. (2015), for $\mathrm{NH}_{3}, \mathrm{H}_{2} \mathrm{~S}, \mathrm{CH}_{4}$, and $\mathrm{N}_{2} \mathrm{O}$. Volatile Organic Compounds (VOC) were determined using a MiniRae 300 PID analyzer equipped with a $9.8 \mathrm{eV}$ lamp (RAE Systems MiniRAE 3,000, San José, CA, United States).

The biomethane potential was analyzed as described elsewhere (Barrena et al., 2018). Inoculum was collected in the wastewater treatment plant (Sabadell, Barcelona), contained $2.8 \%$ dry solids and $65.5 \%$ volatile solids, and was mixed in to the fermented solids in an inoculum to substrate ratio of $2: 1$ based on the volatile solid.

$\mathrm{pH}$, dry mass content (DM) and organic matter (OM) were measured according to standard methods (US Composting Council, 2001). Methods for colony forming units (CFU) are described elsewhere (Rodríguez et al., 2020).

\section{RESULTS AND DISCUSSION}

\section{Fermentation Performance at 22 and $100 \mathrm{~L}$}

The SLs production process from oil cake was previously developed at lab scale ( $0.5 \mathrm{~L}$ bioreactors) using wheat straw as support, as reported by Jiménez-Peñalver et al. (2016) and Rodríguez et al. (2020), obtaining yields close to $0.2 \mathrm{~g} \mathrm{SL} \mathrm{g}^{-1}$ substrate and productivities around $2.7 \mathrm{~g} \mathrm{SL} \mathrm{L}^{-1} \mathrm{~d}^{-1}$ when fermenting at a constant temperature of $30^{\circ} \mathrm{C}$. Maintaining a constant temperature of 33 and $36^{\circ} \mathrm{C}$ in the fermentation dramatically decreased SL yield around 65 and $80 \%$ respectively, although overall biological activity, measured as cumulative oxygen consumption, was maintained (JiménezPeñalver, 2017).

Figure 1 presents the fermentation profiles obtained for the first two replicates undertaken in the $22 \mathrm{~L}$ bioreactor. SLs production was observed from day 3 , together with an overall increase in CFU of 2 orders of magnitude. Moisture did not change significantly in the closed fermenter supplied with watersaturated air. $\mathrm{pH}$ dropped from initial 5.6 to final 3.3, as extensively reported for this production process in both submerged and solid-state fermentations, due to the metabolic activity of the yeast (Daverey and Pakshirajan, 2010; JiménezPeñalver et al., 2016). Final SL yield after 7 days was 0.174 and $0.185 \mathrm{~g} \mathrm{SL} \mathrm{g}^{-1} \mathrm{DMi}$ in replicates 1 and 2, respectively. Growth of fungi was observed at the end of the fermentation when counting final CFU, although it was not clear to which extent this affected SLs production.

Replicate 3 was not sampled until the end of fermentation, to avoid contamination. As expected, no significant fungi growth was detected. $\mathrm{pH}$ dropped to similar values than those seen in replicates 1 and 2 . Overall performance of the fermentation was similar, according to OUR profiles that showed maximum sOUR between 48 and $60 \mathrm{~h}$ ranging from 3.6 to $4 \mathrm{mg} \mathrm{O}_{2} \mathrm{~g}^{-1} \mathrm{DMi} \mathrm{h}^{-1}$.

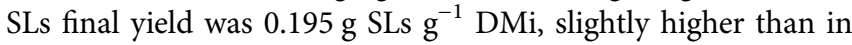
replicates 1 and 2 .

Significant $\mathrm{T}$ gradients were measured during fermentation (Figure 2). Maximum temperatures of 40,38 , and $36^{\circ} \mathrm{C}$ were observed in replicates 1,2 , and 3 , respectively. Increasing airflow up to $31.7 \mathrm{~L} \mathrm{~kg}^{-1} \mathrm{~h}^{-1}$ efficiently decreased the temperature from $33-38^{\circ} \mathrm{C}$ to $19-26^{\circ} \mathrm{C}$ in replicate 1 . For this reason and given the overall decrease of biological activity after 5 days of fermentation, initial airflow was restored in this replicate. To avoid the sharpened temperature variations associated to sampling episodes and cooling capacity, in the following $\mathrm{R} 22$ replicates airflow was increased to a lower value of $26.2 \mathrm{~L} \mathrm{~kg}^{-1} \mathrm{~h}^{-1}$. As can be observed in Figure 2, this strategy allowed for the temperature to be kept in a convenient range without pronounced changes. Maximum temperature gradient observed at a given time was $10^{\circ} \mathrm{C}$ for $\mathrm{R} 22$ replicates 1 and 2 and only $7.5^{\circ} \mathrm{C}$ in replicate 3 , where no mixing occurred.

Despite the fact that temperatures reached over 30 and $36^{\circ} \mathrm{C}$, SLs production yields were similar to those previously obtained at lab scale under controlled temperature. These results point to the yeast's capacity to thrive in a dynamic temperature profile. 

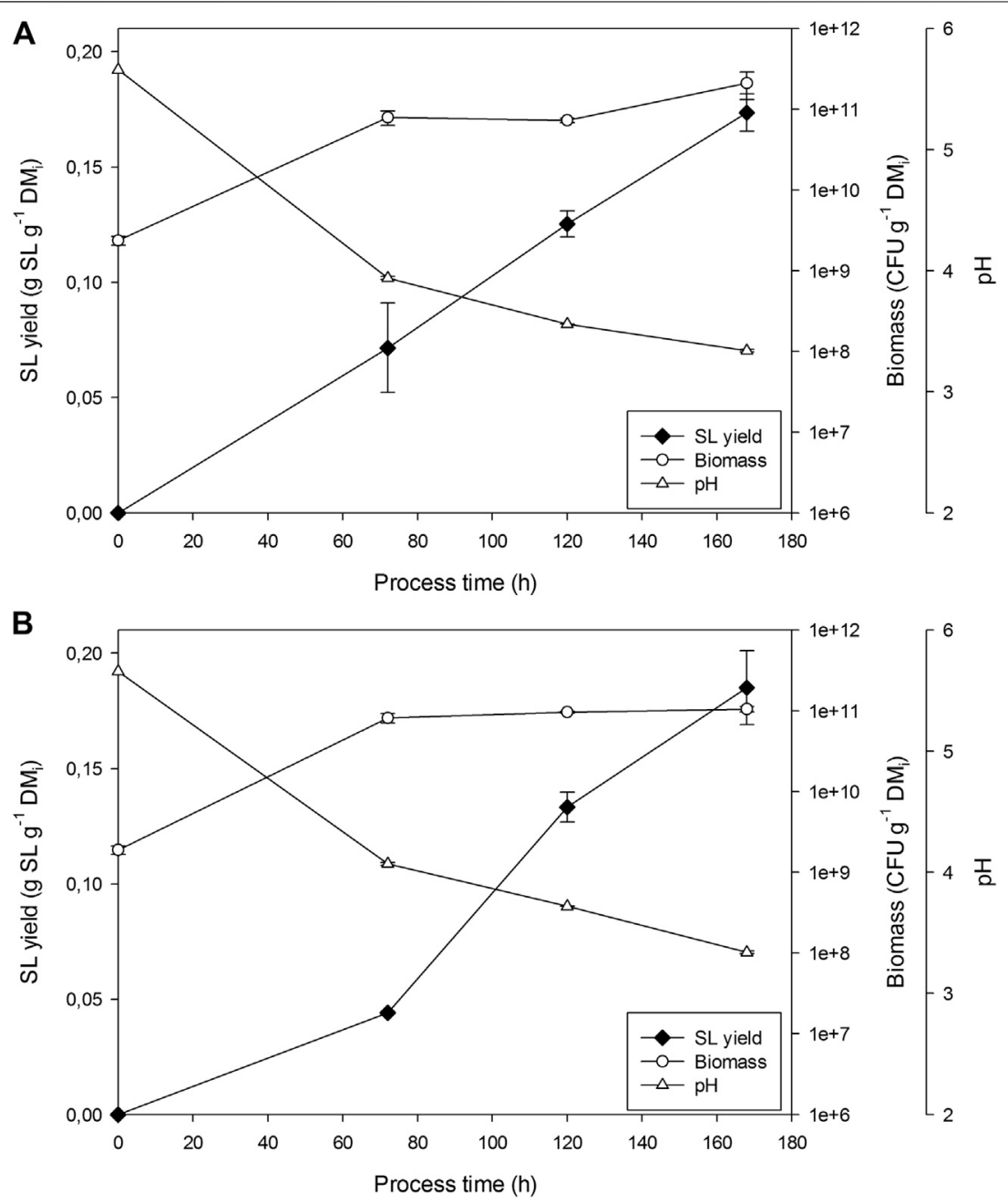

FIGURE 1 | Sophorolipids, pH and CFU evolution in fermentations in R22 for (A) replicate 1 and (B) replicate 2.

Figure 3 presents the results for the two replicates undertaken in the $100 \mathrm{~L}$ bioreactors. $\mathrm{pH}$ dropped from 5.9 to 3.5 in 7 days. Similar biomass growths (CFU/gDM) were obtained at 100 and $22 \mathrm{~L}$. However, SL yield was on average $25 \%$ lower $(0.133$ and $\left.0.142 \mathrm{~g} \mathrm{SL} \mathrm{g}^{-1} \mathrm{DMi}\right)$. Fungi growth was detected in samples from day 6 of fermentation.

The maximum temperatures reached were 43 and $38^{\circ} \mathrm{C}$ in replicate 1 and 2 , respectively (Figure 4 ). In both cases, airflow was increased from 20 to $34.4 \mathrm{~L} \mathrm{~kg}^{-1} \mathrm{~h}^{-1}$ after $48 \mathrm{~h}$ of fermentation (maximum aeration capacity of the airflow meters in the system). Despite specific aeration being 30\% higher than that used in R22, it was insufficient to keep temperatures below $35^{\circ} \mathrm{C}$. Differences in temperature among R100 measured points reached $20^{\circ} \mathrm{C}$ and $17.5^{\circ} \mathrm{C}$ in replicate 1 and 2, respectively, doubling those observed in R22.

Although agitation was not planned initially, it was decided to provide some mixing to the mixture to help the dissipation of heat. The mixer was activated after $93 \mathrm{~h}$ of fermentation for $2 \mathrm{~min}$ at $5 \mathrm{~Hz}$ to increase heat dissipation. This action produced a fleeting temperature drop, however the temperature increased to over $40^{\circ} \mathrm{C}$ afterward. In our previous work at lab scale (Jiménez-Peñalver et al., 2016) we demonstrated how intermittent mixing has a positive effect on SLs yield because it improves the availability of substrates to the yeast and increases microbial activity, as measured by sOUR. In R100 this same mechanism produced an excess of metabolic heat that accumulated in the system, leading to excessive temperature for SLs production by S. bombicola. The effectiveness of cooling through the bioreactor walls is reduced when bioreactor diameter increases (Perez et al., 2019). The external surface to volume ratio of $\mathrm{R} 100$ is $53 \%$ that of R22, thus displaying a much lower heat dissipation capacity. It is necessary to compensate the reduction of surface/volume ratio with much higher aeration or other dissipation mechanisms. For instance, Pitol et al. (2016) supplied cooler air when the temperature rose to over $35^{\circ} \mathrm{C}$ to successfully control temperature and maximize enzyme activity at $200 \mathrm{~L}$ SSF. Biz et al. (2016) used a humidification column. Nagel et al. (2001) combined continuous reactor mixing, reactor wall cooling, and 


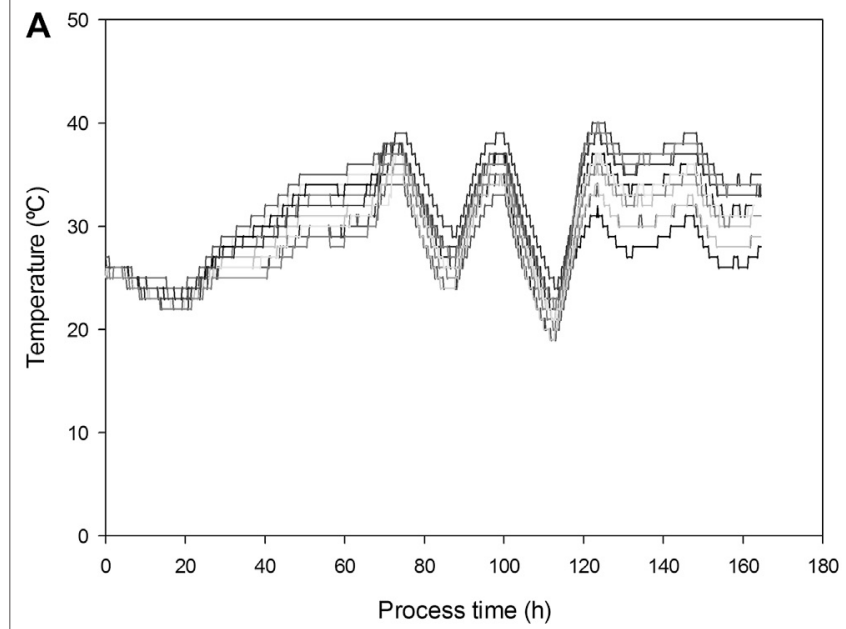

B

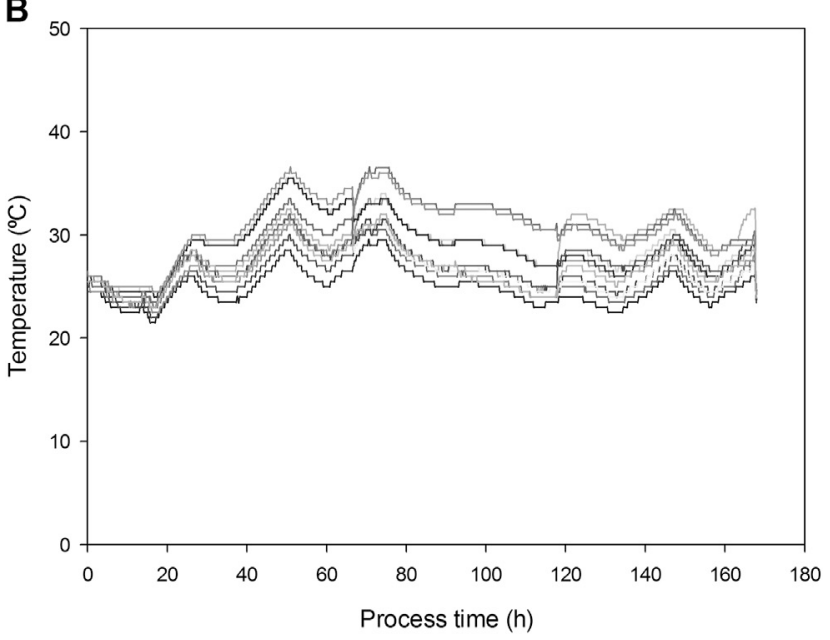

C

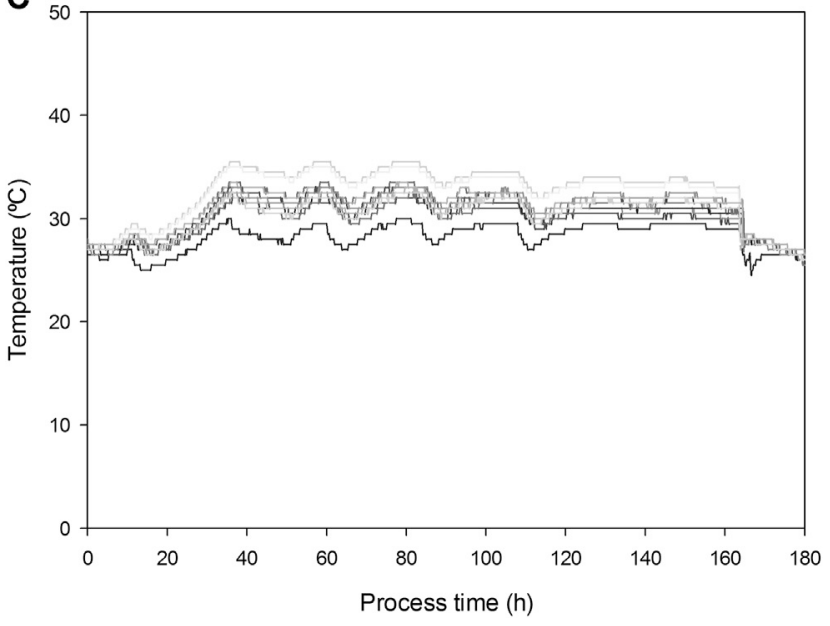

FIGURE 2 | Temperature gradients measured in 13 different points for R22 replicates (A) 1; (B) 2; and (C) 3.

evaporative cooling. As a consequence, extra energy consumption will be necessary to control the temperature in a suitable range by combining one or more of these strategies with forced aeration. This must be considered in the preliminary cost analysis.

Superficial air velocity has been suggested and used as a scaleup criteria in SSF (Mejias et al., 2020). The aeration conditions in R100 were equivalent to a value of superficial velocity of $3.56 \mathrm{~m} / \mathrm{h}$ which was almost $50 \%$ higher than that used in R22 replicates 2 and 3. So the criteria of keeping the same superficial velocity when scaling up is not sufficient to maintain suitable temperature conditions in this case.

\section{Scale Comparison}

Table 1 compares SLs yields and productivities previously obtained at lab scale (Rodríguez et al., 2020) with the values obtained in this current study for R22 and R100.

Despite reaching temperatures over $35^{\circ} \mathrm{C}, \mathrm{R} 22$ showed higher, but not statistically different, yields and productivities to those of experiments at lab scale under a controlled temperature of $30^{\circ} \mathrm{C}$. S. bombicola was able to thrive in this dynamic temperature change, and SLs production was only affected when sharp changes were provoked by excessive aeration and mixing. R100 yields and productivities were lower but not statistically different to those at lab scale. The higher thermal amplitude affected overall performance. Adopting strategies to control temperature gradients would aid the scale-up process and will be considered in further studies.

\section{Process Emissions}

Process emissions can severely impact the environment. VOCs (generally organosulfur compounds, nitrogenous compounds, ketones, and terpenes), $\mathrm{NH}_{3}, \mathrm{H}_{2} \mathrm{~S}, \mathrm{~N}_{2} \mathrm{O}$, and $\mathrm{CH}_{4}$ are the main gases emitted during SSF processes and may be responsible for producing air pollution and bad odors if the proper treatment is not provided (Maulini-Duran et al., 2015). All these gaseous compounds are related to the biological decomposition of organic matter, nitrogen, and sulfur-based compounds (González et al., 2019). Characterizing these emissions is essential to selecting the suitable gas treatment technology type and design, which must be included in the economic and environmental analysis.

Gaseous emissions generated during the production of SL through SSF, were analyzed in two R22 experiments (replicates 1 and 2) and are presented in Figure 5 as punctual emission. Maximum total VOCs emission of $5.0 \cdot 10^{-2}$ and $1.14 \cdot 10^{-1} \mathrm{mg}$ of VOCs $\mathrm{g}^{-1}$ DMi were detected in replicates 1 and 2, respectively; followed by $\mathrm{NH}_{3}$ with $1.54 \cdot 10^{-2}$ and $1.34 \cdot 10^{-2} \mathrm{mg} \mathrm{NH} \mathrm{g}^{-1} \mathrm{DMi}$, and in a lesser presence $\mathrm{CH}_{4}$ with $6.75 \cdot 10^{-3}$ and $4.82 \cdot 10^{-3} \mathrm{mg}$ of $\mathrm{CH}_{4} \mathrm{~g}^{-1} \mathrm{DMi}$, in replicates 1 and 2, respectively. Finally, the presence of $\mathrm{N}_{2} \mathrm{O}$ was only residually detected in the $\mathrm{R} 22$ (replicate 1 ) with a total emission $1.0 \cdot 10^{-3} \mathrm{mg}$ of $\mathrm{N}_{2} \mathrm{O} \mathrm{g} \mathrm{g}^{-1} \mathrm{DMi}$ and $\mathrm{H}_{2} \mathrm{~S}$ was not detected in any of the experiments.

References to emissions of SSF processes, using WOC and MOL as substrates, could not be found in the literature. Only MauliniDuran et al. (2015) reported emissions for different SSF processes, including a fermentation process using WOC mixed with raw 

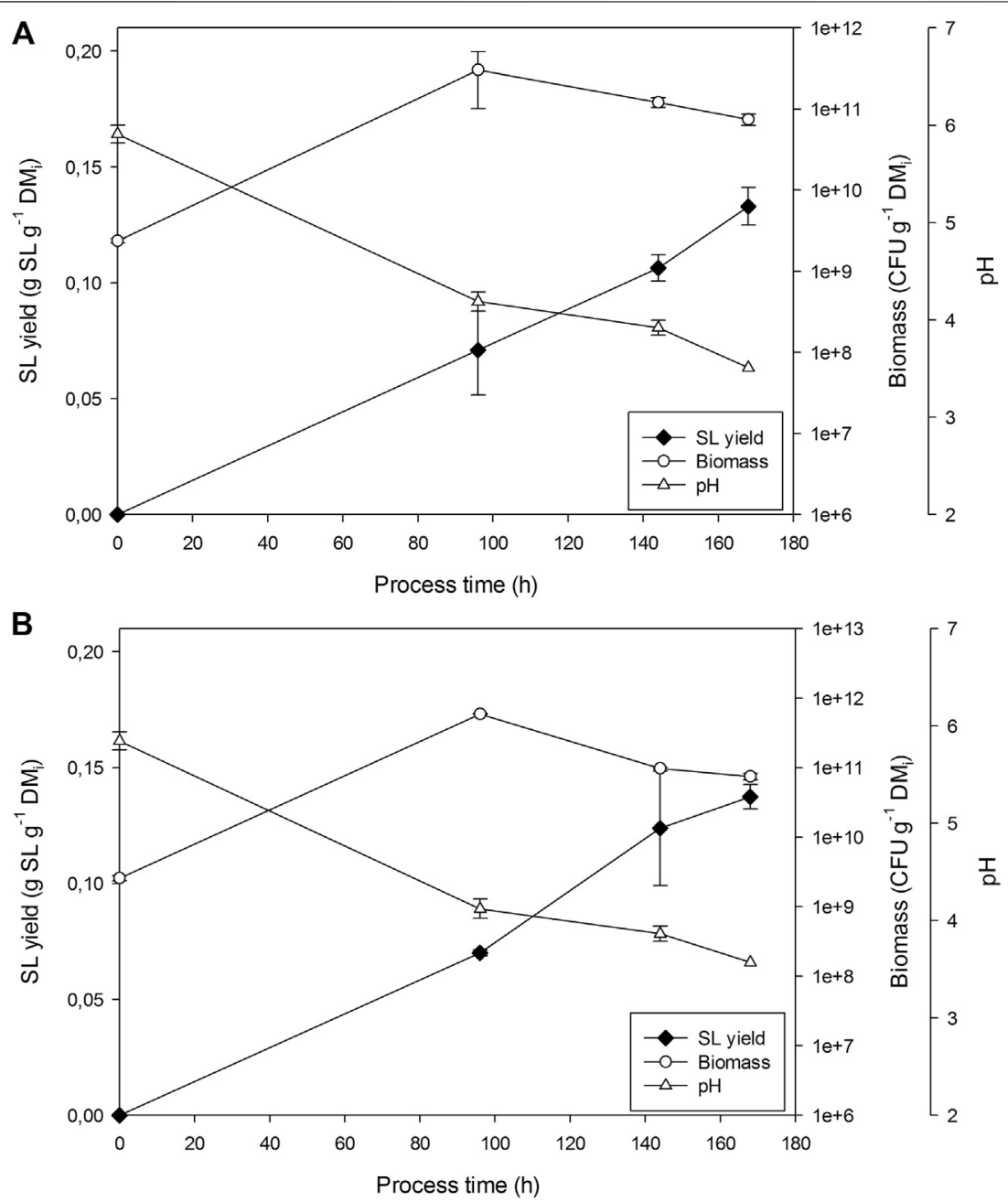

FIGURE 3 | Sophorolipids, pH and CFU evolution in fermentations in R100 for (A) replicate 1 and (B) replicate 2.

sludge to produce lipases. In this work, the authors reported VOCs emissions during SSF of different substrates ranging from 0.2 to $18 \mathrm{mg} \mathrm{g}^{-1} \mathrm{DM}$. Therefore, emissions during SL production are lower than those reported for e.g., WOC + raw sludge $\left(0.28 \mathrm{mg} \mathrm{g}^{-1}\right.$ $\mathrm{DMi})$. Methane emissions are related to the presence of anaerobic zones, caused either due to excessive humidity, insufficient porosity, or inappropriate aeration (Puyuelo et al., 2010). Furthermore, the shrinkage of solids has been reported when increasing bed height (Perez et al., 2019). In our case, water content was adjusted to $75 \%$ of the WHC of the solid's mixture, no leachate was produced, air-filled porosity was sufficient, and oxygen levels were over $14.8 \%$ in all cases. However, at the end of the fermentation solids compacted against the bioreactor baffles, due to the shear stress of agitation, were detected. These compacted volumes may have met the necessary anaerobic conditions for methane production, also indicating the presence of methanogenic bacteria. Obtained emission values for methane $\left(6.75 \cdot 10^{-3}\right.$ and $4.82 \cdot 10^{-3} \mathrm{mg}$ of $\mathrm{CH}_{4}$ $\left.\mathrm{g}^{-1} \mathrm{DMi}\right)$ are in the range of those reported by Maulini-Duran et al., 2015 (3 $10^{-3}$ to $\left.2210^{-3} \mathrm{mg} \mathrm{CH}_{4} \mathrm{~g}^{-1} \mathrm{DMi}\right)$.
Emissions related to nitrogen cycle $\left(\mathrm{NH}_{3}\right.$ and $\left.\mathrm{N}_{2} \mathrm{O}\right)$ are obviously related to the presence of nitrogen in the processed substrates. Maulini-Duran et al., 2015 reported 0 to $3.2 \mathrm{mg}$ of $\mathrm{NH}_{3} \mathrm{~g}^{-1}$ DMi and $2 \cdot 0^{-3}$ to $8 \cdot 10^{-3} \mathrm{mg}$ of $\mathrm{N}_{2} \mathrm{O} \mathrm{g}^{-1} \mathrm{DMi}$, as those obtained in SL production in the lower range.

Since these values are in a low range, a simple biofiltration system would be sufficient for the abatement of this emissions (Pagans et al., 2007).

\section{Biomethane Potential of Spent Fermented Solids}

Final spent fermented solids, after acetate evaporation, were evaluated for biogas production to assess and facilitate its external management or, if possible, to be used on-site as an energy source. The fermented solids after SLs extraction contain not only wheat straw but also yeast biomass and unconsumed substrates. During SSF of WOC the total fat consumption was quantified as $60 \%$ (Jiménez-Peñalver et al., 2016). 

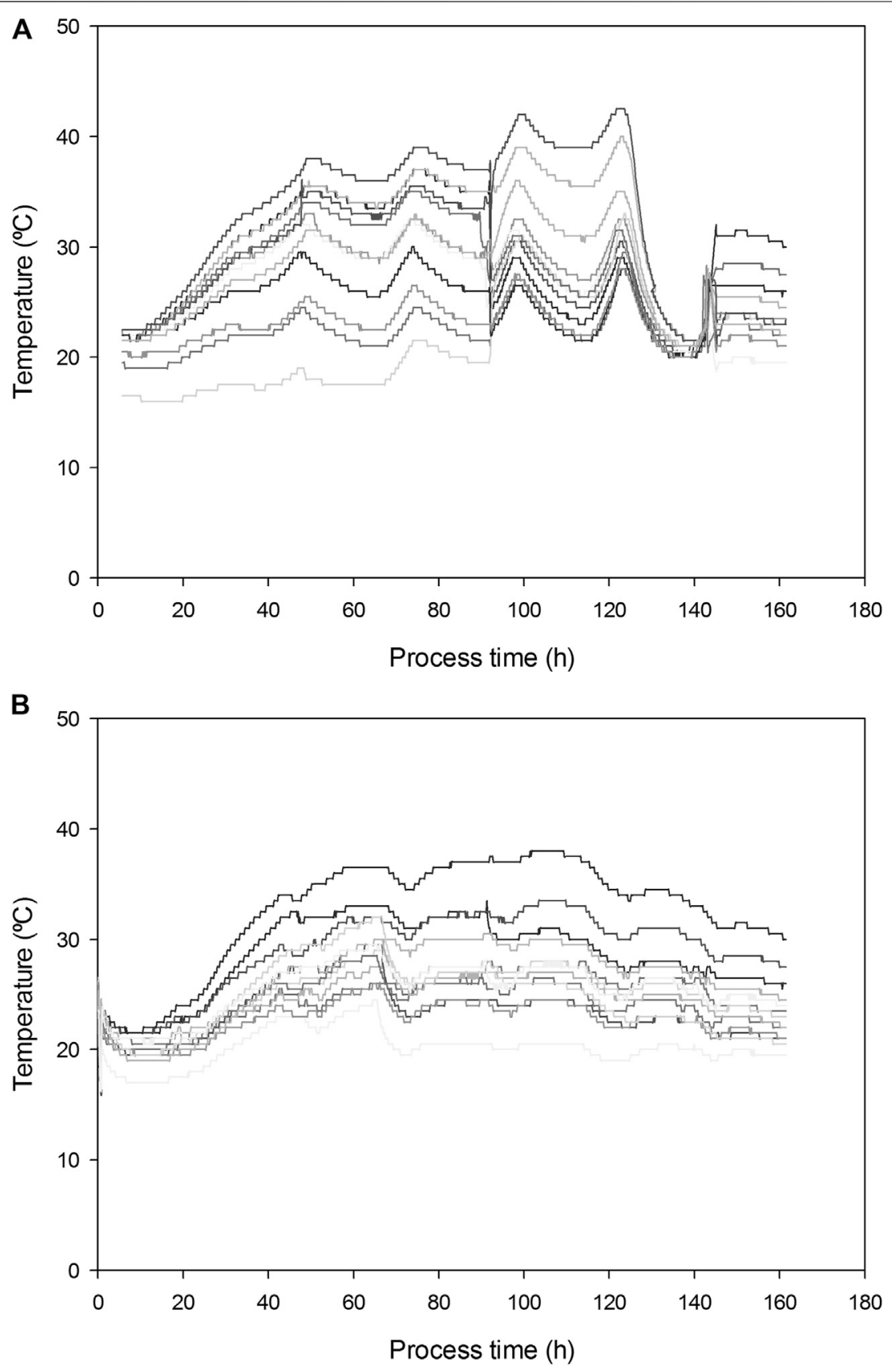

FIGURE 4 | Temperature gradients measured in 13 different points for R100 replicates (A) 1; (B) 2.

The cumulative methane production of spent fermented solids is presented in Figure 6. A total of $232.5 \mathrm{~L} \mathrm{CH}_{4} \mathrm{~kg}^{-1} \mathrm{SV}$ were obtained after 43 days. Adjusting methane evolution to the modified Gompertz model (Nielfa et al., 2015) provided a methane potential of $225.84 \mathrm{~L}$ $\mathrm{CH}_{4} \mathrm{~kg}^{-1} \mathrm{SV}$ (Figure 6). The biogas potential of a mixture, like the spent fermented solids from this study, has not been reported in literature. However, the value can be compared to other agriproducts. Tong et al. (1990) reported on $332 \mathrm{~L} \mathrm{CH}_{4} \mathrm{~kg}^{-1} \mathrm{SV}$ when using wheat straw as substrate while Cui et al. (2011) compared methane production in clean wheat straw and wheat straw with horse manure residues, obtaining values of 90 and $150 \mathrm{~L} \mathrm{CH}_{4} \mathrm{~kg}^{-1} \mathrm{SV}$, respectively. Therefore, obtained values in this work are in the range of similar mixtures. Moreover, these results show that the fermented spent solids present a methane potential like that reported for the organic fraction of municipal solid wastes (Abad et al., 2019), which through the management of anaerobic digestion is widely implemented in different countries at a commercial level. Thus, anaerobic digestion could be a suitable technology for spent solids valorization, which, combined with composting would represent a satisfactory zero waste strategy to combine with SSF. 
TABLE 1 | Comparison of maximum yields (obtained at 7 days) and maximum productivities (as measured after 5 days except for R100 at 6 days) at lab scale, R22 and R100. Different letters indicate values statistically different $(p<0.05)$.

\begin{tabular}{|c|c|c|c|}
\hline Production & Lab scale $(0.5 \mathrm{~L})^{\star}$ & R22 & R100 \\
\hline Yield $\mathrm{g} \mathrm{SL} \mathrm{g}^{-1} \mathrm{DMi}$ & $0.16^{\mathrm{ab}}$ & $0.19^{a}$ & $0.14^{b}$ \\
\hline Productivity $\mathrm{g} \mathrm{SL} \mathrm{g}^{-1} \mathrm{DMi} \mathrm{d}^{-1}$ & 0.028 & 0.026 & 0.021 \\
\hline Yield g SL $L^{-1}$ & $14.8^{\mathrm{cd}}$ & $17.6^{\mathrm{c}}$ & $14.0^{\mathrm{cd}}$ \\
\hline Productivity $\mathrm{g} \mathrm{SL} \mathrm{L}^{-1} \mathrm{~d}^{-1}$ & 2.747 & 2.534 & 2.016 \\
\hline Yield $\mathrm{g} \mathrm{SL} \mathrm{g}^{-1}$ initial substrate & $0.21^{\text {ef }}$ & $0.24^{\mathrm{e}}$ & $0.19^{f}$ \\
\hline Productivity $\mathrm{g} S \mathrm{~L} \mathrm{~g}^{-1}$ initial substrate $\mathrm{d}^{-1}$ & 0.038 & 0.035 & 0.028 \\
\hline
\end{tabular}

Source: Rodríguez et al. (2020).

\section{Process Overview}

Table 2 shows the general inventory to produce SLs through SSF from WOC and MOL using WS as support. From this data it will be possible to perform environmental and techno economic studies of the presented process. Considering productivity values, total fermentation time is stablished at 7 days.

Some literature can be found regarding LCA of SL production under submerged fermentation $(\mathrm{SmF})$ but none under SSF. Hu et al. (2021) and Kopsahelis et al. (2018) presented the corresponding inventory, reporting data on system inputs and outputs. In these studies, inventories are mainly based on energy consumption and materials used for
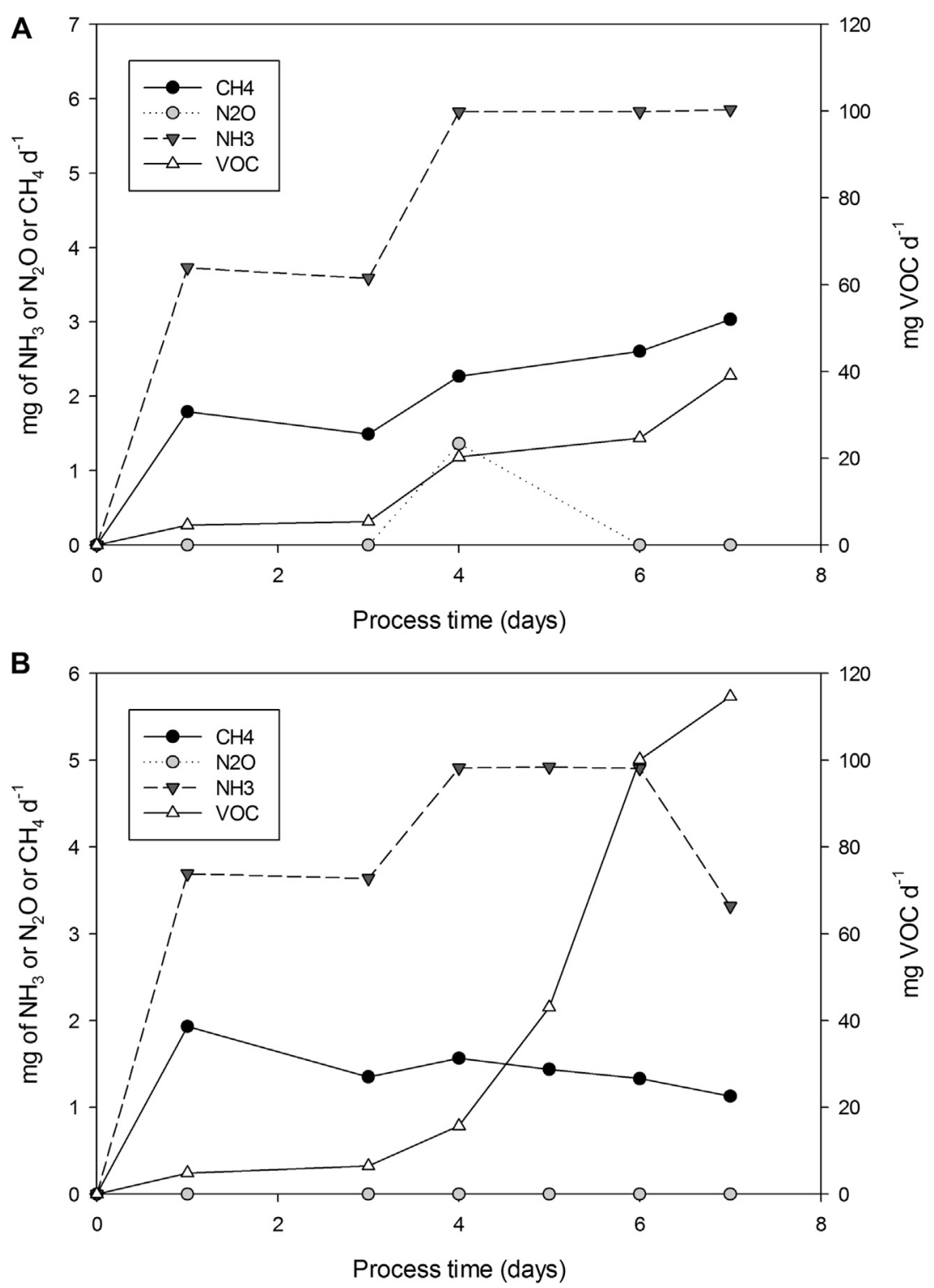

FIGURE 5 | Punctual emissions $\left(\mathrm{mg} \mathrm{d}^{-1}\right)$ of $\mathrm{CH}_{4}$, VOC, $\mathrm{NH}_{3}$ and $\mathrm{N}_{2} \mathrm{O}$ for experiments R22 replicates 1 and 2. 


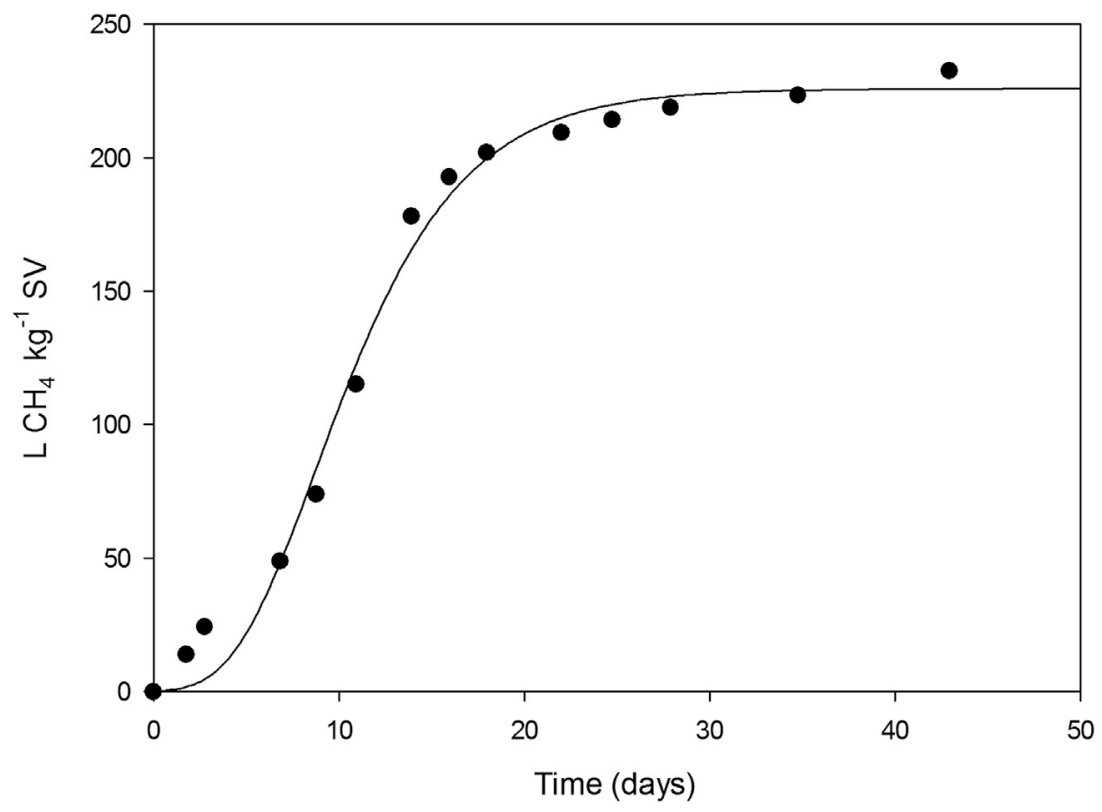

FIGURE 6 | Methane potential production for spent fermented solids and adjustment of Gompertz model.

TABLE 2 | Inputs and Outputs to a R22 batch process to produce sophorolipids through Solid State Fermentation. All values referred to the production of $1 \mathrm{~kg}$ of sophorolipid.

\section{Inputs}

Inoculum preparation

Water

Glucose

Peptone

Malt extract

Yeast extract

Energy consumption

SSF process

Wheat straw

Winterization oil cake

Molasses

Water

Mixture moisture

Air (0-72 h)

Air (72-168 h)

Extraction

Ethyl acetate

Hexane

Energy consumption

Water consumption

Outputs

Fermented mixture

Fermented mixture moisture

Sophorolipid

Ethyl acetate losses

Waste hexane

Methane

Nitrous oxide

VOC

Ammonia
5.6

\subsection{1}

9.10

4.55

2.73

2.73

0.153

1.99

3.30

082

3.67

46.15

4,265

184.8

38.96

0.558

12.76

9.73

46.4

1

9.65

38.96

0.033-0.049

0.007

0.365-0.775
$0.091-0.112$ the inoculum preparation and fermentation process, however, gaseous emissions (VOCs, $\mathrm{CH}_{4}, \ldots$ ) or valorization of wastes are not included. According to these studies, energy consumption ranges between 214 and $676 \mathrm{kWh}$ for the production of $1 \mathrm{~kg}$ of SL, including the inoculum preparation. These values are higher than those reported in this current study. Differences can be attributed to the fact that our approximation is based on bench-scale equipment, but also to the differences between the processes. SmF systems usually include permanent agitation and higher pressure drops regarding aeration, while we considered intermittent agitation and pressure drops to be lower in solid porous matrices.

\section{CONCLUSION}

Production of SLs by SSF with Starmerella bombicola, from oil cake and molasses using wheat straw as a support was assessed at a representative bench scale of 22 and $100 \mathrm{~L}$. Despite the occurrence of significant temperature gradients, it was possible to reach yields and productivities similar to those previously obtained at lab scale. Thus, implementing efficient temperature control strategies would allow for a successful process scale up. Gaseous emissions of the process were in the lower range of those reported for similar processes. The methane potential of the spent solids was similar to that of organic fractions of municipal solid waste and thus anaerobic digestion could be considered as a valorization strategy for a zero-waste process.

All the obtained information has been gathered in an inventory that would be the basis for a preliminary economic and environmental assessment, to confirm the benefits of the 
proposed production process and to locate opportunities for improvement prior to scaling up to a pilot scale.

\section{DATA AVAILABILITY STATEMENT}

The original contributions presented in the study are included in the article/Supplementary Material, further inquiries can be directed to the corresponding author.

\section{AUTHOR CONTRIBUTIONS}

AR performed the experiments. TG and XF wrote the manuscript. All authors participated in the experimental design, analyzed the data and discussed the results.

\section{REFERENCES}

Abad, V., Avila, R., Vicent, T., and Font, X. (2019). Promoting circular economy in the surroundings of an organic fraction of municipal solid waste anaerobic digestion treatment plant: biogas production impact and economic factors. Bioresour. Tech. 283, 10-17. doi:10.1016/j.biortech.2019. 03.064

Baccile, N., Babonneau, F., Banat, I. M., Ciesielska, K., Cuvier, A.-S., Devreese, B., et al. (2016). Development of a cradle-to-grave approach for acetylated acidic sophorolipid biosurfactants. ACS Sustain. Chem. Eng. 5, 1186-1198. doi:10. 1021/acssuschemeng.6b02570

Banat, I. M., Satpute, S. K., Cameotra, S. S., Patil, R., and Nyayanit, N. V. (2014). Cost effective technologies and renewable substrates for biosurfactants' production. Front. Microbiol. 5, 697. doi:10.3389/fmicb. 2014.00697

Banat, I. M., Carboué, Q., Saucedo-Castañeda, G., and de Jesús Cázares-Marinero, J. (2021). Biosurfactants: the green generation of speciality chemicals and potential production using Solid-State fermentation (SSF) technology. Bioresour. Tech. 320, 124222. doi:10.1016/j.biortech.2020.124222

Barrena, R., Traub, J. E., Gil, C. R., Goodwin, J. A. S., Harper, A. J., Willoughby, N. A., et al. (2018). Batch anaerobic digestion of deproteinated malt whisky pot ale using different source inocula. Waste Manage. 71, 675-682. doi:10.1016/j. wasman.2017.06.025

Biz, A., Finkler, A. T. J., Pitol, L. O., Medina, B. S., Krieger, N., and Mitchell, D. A. (2016). Production of pectinases by solid-state fermentation of a mixture of citrus waste and sugarcane bagasse in a pilot-scale packed-bed bioreactor. Biochem. Eng. J. 111, 54-62. doi:10.1016/j.bej.2016.03.007

Cui, Z., Shi, J., and Li, Y. (2011). Solid-state anaerobic digestion of spent wheat straw from horse stall. Bioresour. Technol. 102 (20), 9432-9437. doi:10.1016/j. biortech.2011.07.062

da Cunha, L. P., Casciatori, F. P., Vicente, I. V., Garcia, R. L., and Thoméo, J. C. (2020). Metarhizium anisopliae conidia production in packed-bed bioreactor using rice as substrate in successive cultivations. Process Biochem. 97, 104-111. doi:10.1016/j.procbio.2020.07.002

Daverey, A., and Pakshirajan, K. (2010). Sophorolipids from Candida bombicola using mixed hydrophilic substrates: production, purification and characterization. Colloids Surf. B Biointerfaces 79, 246-253. doi:10.1016/j. colsurfb.2010.04.002

Daverey, A., Pakshirajan, K., and Sumalatha, S. (2011). Sophorolipids production by Candida bombicola using dairy industry wastewater. Clean. Techn Environ. Pol. 13, 481-488. doi:10.1007/s10098-010-0330-4

Gea, T., Ferrer, P., Alvaro, G., Valero, F., Artola, A., and Sánchez, A. (2007). Cocomposting of sewage sludge: fats mixtures and characteristics of the lipases involved. Biochem. Eng. J. 33 (3), 275-283. doi:10.1016/j.bej.2006.11.007

González, D., Guerra, N., Colón, J., Gabriel, D., Ponsá, S., and Sánchez, A. (2019). Filling in sewage sludge biodrying gaps: greenhouse gases, volatile organic compounds and odour emissions. Bioresource Technol. 291, 121857.

\section{FUNDING}

Authors wish to thank the Spanish Ministerio de Economía y Competitividad (Project CTM2015- 69513-R) for financial support. Alejandra Rodríguez appreciates and thanks the National Council for Science and Technology (CONACYT) México for the scholarship awarded for her $\mathrm{PhD}$ studies.

\section{SUPPLEMENTARY MATERIAL}

The Supplementary Material for this article can be found online at: https://www.frontiersin.org/articles/10.3389/fceng.2021.632752/ full\#supplementary-material.

Hu, X., Subramanian, K., Wang, H., Roelants, S. L. K. W., To, M. H., Soetaert, W., et al. (2021). Guiding environmental sustainability of emerging bioconversion technology for waste-derived sophorolipid production by adopting a dynamic life cycle assessment (dLCA) approach. Environ. Pollut. 269, 116101. doi:10. 1016/j.envpol.2020.116101

Jiménez-Peñalver, P., Gea, T., Sánchez, A., and Font, X. (2016). Production of sophorolipids from winterization oil cake by solid-state fermentation: optimization, monitoring and effect of mixing. Biochem. Eng. J. 115, 93-100. doi:10.1016/j.bej.2016.08.006

Jiménez-Peñalver, P., Rodríguez, A., Daverey, A., Font, X., and Gea, T. (2019). Use of wastes for sophorolipids production as a transition to circular economy: state of the art and perspectives. Rev. Environ. Sci. Biotechnol. 18, 413-435. doi:10. 1007/s11157-019-09502-3

Jiménez-Peñalver, P. (2017). Sophorolipids production by solid-state fermentation: from lab-scale to pilot plant. $\mathrm{PhD}$ thesis. Bellaterra (Spain): Universitat Autònoma de Barcelona.

Kopsahelis, A., Kourmentza, C., Zafiri, C., and Kornaros, M. (2018). Gate-to-gate life cycle assessment of biosurfactants and bioplasticizers production via biotechnological exploitation of fats and waste oils. J. Chem. Technol. Biotechnol. 93, 2833-2841. doi:10.1002/jctb.5633

Maulini-Duran, C., Abraham, J., Rodríguez-Pérez, S., Cerda, A., Jiménez-Peñalver, P., Gea, T., et al. (2015). Gaseous emissions during the solid state fermentation of different wastes for enzyme production at pilot scale. Bioresour. Technol. 179, 211-218. doi:10.1016/j.biortech.2014.12.031

Mejias, L., Estrada, M., Barrena, R., and Gea, T. (2020). A novel two-stage aeration strategy for Bacillus thuringiensis biopesticide production from biowaste digestate through solid-state fermentation. Biochem. Eng. J. 161, 107644. doi:10.1016/j.bej.2020.107644

Mitchell, D. A., Krieger, N., and Berovic, M. (2006). Solid-state fermentation bioreactors: fundamentals of design and operation. Berlin: Springer.

Nagel, F. J., Tramper, J., Bakker, M. S., and Rinzema, A. (2001). Temperature control in a continuously mixed bioreactor for solid-state fermentation. Biotechnol. Bioeng. 72, 219-230. doi:10.1002/1097-0290(20000120)72:2<219::aid-bit10>3.0.co;2-t

Nielfa, A., Cano, R., and Fdz-Polanco, M. (2015). Theoretical methane production generated by the co-digestion of organic fraction municipal solid waste and biological sludge. Biotechnol. Rep. 5, 14-21. doi:10.1016/j. btre.2014.10.005

Pagans, E., Font, X., and Sánchez, A. (2007). Coupling composting and biofiltration for ammonia and volatile organic compound removal. Biosyst. Eng. 97, 491-500. doi:10.1016/j.biosystemseng.2007.03.035

Perez, C. L., Casciatori, F. P., and Thoméo, J. C. (2019). Strategies for scaling-up packed-bed bioreactors for solid-state fermentation: the case of cellulolytic enzymes production by a thermophilic fungus. Chem. Eng. J. 361, 1142-1151. doi:10.1016/j.cej.2018.12.169

Pitol, L. O., Biz, A., Mallmann, E., Krieger, N., and Mitchell, D. A. (2016). Production of pectinases by solid-state fermentation in a pilot-scale packed-bed bioreactor. Chem. Eng. J. 283, 1009-1018. doi:10.1016/j.cej. 2015.08.046 
Puyuelo, B., Gea, T., and Sánchez, A. (2010). A new control strategy for the composting process based on the oxygen uptake rate. Chem. Eng. J. 165 (1), 161-169. doi:10.1016/j.cej.2010.09.011

Rodríguez, A., Gea, T., Sánchez, A., and Font, X. (2020). Agro-wastes and inert materials as supports for the production of biosurfactants by solid-state fermentation. Waste Biomass Valor. doi:10.1007/s12649-020-01148-5

Tong, X., Smith, L. H., and McCarty, P. L. (1990). Methane fermentation of selected lignocellulosic materials. Biomass 21 (4), 239-255. doi:10.1016/0144-4565(90) 90075-u

US Composting Council (2001). Test methods for the examination of composting and compost. Houston: Edaphos International.

Wang, H., Tsang, C.-W., To, M. H., Kaur, G., Roelants, S. L. K. W., Stevens, C. V., et al. (2020). Techno-economic evaluation of a biorefinery applying food waste for sophorolipid production-a case study for Hong Kong. Bioresour. Tech. 303, 122852. doi:10.1016/j.biortech.2020.122852

Conflict of Interest: The authors declare that the research was conducted in the absence of any commercial or financial relationships that could be construed as a potential conflict of interest.

Copyright $\odot 2021$ Rodríguez, Gea and Font. This is an open-access article distributed under the terms of the Creative Commons Attribution License (CC BY). The use, distribution or reproduction in other forums is permitted, provided the original author(s) and the copyright owner(s) are credited and that the original publication in this journal is cited, in accordance with accepted academic practice. No use, distribution or reproduction is permitted which does not comply with these terms. 